УДК $78.072+781.5$

\author{
Анна Васильевна Полищук, \\ аспирантка кафедры теории музыки
}

Национальной музыкальной академии Украины имени П. И. Чайковского

odma_n@ukr.net

\title{
АКТУАЛЬНЫЕ ВОПРОСЫ СИСТЕМНОГО ПОДХОДА В СОВРЕМЕННОМ МУЗЫКОЗНАНИИ
}

Цель статьи: рассмотрение системного подхода к изучению музыкальных явлений современности в отечественном музыкознании. Методология: в работе применены источниковедческий, компаративный и системный подходы. Научная новизна: в контексте изучения музыкальных явлений современности рассматриваются такие понятия, как музыкально-теоретическая и музыкально-практическая системы, система профессионального исполнительства, системность феноменов исполнительской и композиторской школ, системный метод исследования. В качестве выводов предлагается вариант методической организации анализа музыкального произведения, поэтапную основу которого составляют логические принципы многоуровневого иерархического структурирования объекта исследования, т. е. произведения, как системы.

Ключевые слова: системный подход, система, методология музыкознания, методическая организация анализа, объект исследования как система.

Polishchuk Anna, graduate student of the department of theory of music, National P. I. Tchaikovsky Academy of Music

Topical issues of a systemic approach in modern musicology

Article purpose is consideration of system approach to studying of the musical phenomena of the present in domestic musicology. Methodology: in work source study, comparative and system approaches are applied. Scientific novelty: in the context of studying of the musical phenomena of the present such concepts as the musical and theoretical and musical and practical systems, the system of professional performance, systemacity of phenomena of performing and composer schools, a system method of a research are considered. As conclusions the option of the methodical organization of the analysis of the piece of music which stage-by-stage basis the logical principles of multilevel hierarchical structuring an object of a research, i.e. works as systems are is offered.

Keywords: system approach, system, methodology of musicology, methodical organization of analysis, the object of study as a system. 
Полішук Анна Василівна, аспірантка кафедри теорії музики Національної музичної академії України імені П. І. Чайковского

Актуальні питання системного підходу в сучасному музикознавстві

Мета статmі: розглядання системного підходу до вивчення музичних явиш сучасності у вітчизняному музикознавстві. Методологія: в работі використані джерелознавчий, компаративний й системний підходи. $\mathbf{H a -}$ укова новизна: в контексті вивчення музичних явищ сучасності розглядаються такі поняття, як музично-теоретична й музично-практична системи, система професійного виконавства, системність феноменів виконавської й композиторської шкіл, системний метод дослідження у якості висновків пропонується варіант методичної організації аналізу музичного твору, поетапну основу якого складають логічні принципи багаторівневого ієрархічного структурування об'єкта дослідження, тобто твору як системи.

Ключові слова: системний підхід, система, методологія музикознавства, методологічна організація аналізу, об'єкт дослідження як система.

Актуальность работы. Как известно, одной из ведущих функций музыкознания является обобщение и систематизация наблюдений, опыта и знаний, накопленных в процессе изучения разнообразных музыкальных явлений. Закономерным представляется то, что чем шире спектр объектов для исследования, тем больше они требуют разработки методологической базы как в направлении дифференцированной специализации методик анализа тех или иных аспектов музыкального искусства и культуры, так и в направлении поиска способов, методов и научных подходов, предназначенных для упорядочивания результатов аналитической деятельности.

Изложение основного материала. В данном контексте на современном этапе прослеживается определённая тенденция, свидетельствующая об актуализации системного подхода и перспективности его применения в теоретическом, историческом, исполнительском и культурологическом музыкознании. При этом особое внимание обращается на то, что применение системного подхода является продуктивным и перспективным именно «в тех областях знания, где уже само по себе принятие общесистемных идей позволяет существенно расширить и уточнить исходное представление об объекте исследования» [3, 203-204]. Такое одновременное сочетание, казалось бы, противоположных направлений - «расширение» и «уточнение» - связано с поиском единообразного анализа разнообразных системных объектов с помощью установления сходства в их структурах и способах функционирования, а также определения различия и индивиду- 
альных особенностей каждой из систем в зависимости от внутренних и внешних закономерностей их бытия.

Одной из наиболее ярких в этом плане стала концепция «музыкально-теоретических систем», которая была представлена в фундаментальных работах Ю. Холопова (Москва) [6], И. Котляревского (Киев) [3] и Г. Вирановского (Одесса) [1]. Эти работы отразили общую для конца XX - начала XXI века тенденцию, характеризующуюся превращением самого научного знания в объект исследования. Кроме того, понятие «музыкально-теоретическая система» фактически сразу получило столь быстрое распространение в отечественном музыкознании, что привело к основанию соответствующих учебных курсов в ведущих музыкальных вузах Киева, Москвы, Одессы и других городов.

Общим для выше названных трёх научных концепций, сформировавшихся в 70-80-е годы прошлого века, было стремление к преодолению обособленности музыкально-теоретических учений и объединению их в системную целостность. Ю. Холопов, обосновывая данный аспект исследования, указывает на специфическую иерархию в структурировании факторов, определяющих содержание музыкально-теоретической системы:

«I. 1. Состояние музыкальной практики.

2. Состояние музыкальной теории.

II. 3. Музыкальная практика, изучаемая теорией.

4. Музыкальная практика - эстетический идеал теории.

III. 5. Влияние дугих наук.

6. Общефилософская и специально-научная методология» (цит. по $[3,7])$.

Через 10 лет, в очередном варианте программы «Музыкально-теоретические системы» для музыкальных вузов [6], Ю. Холопов подчёркивает необходимость объединения в единое, логически непротиворечивое, функионально связанное и центализованное целое, т. е. в систему следующего сложного комлекса, характеризующего компоненты музыкально-теоретического знания:

«1. Онтологизация исторически-конкретной системы художественных ценностей <...>.

2. Формирование общей эмпирической основы теории <...>

3. Номинология и терминология музыкальной теории <...>.

4. Классификация и систематика предметов музыкальной теории $<\ldots>$. Установление логической связи» $[6,16]$. 
Итогом познания Ю. Холопов определяет формирование теории как идеальной модели предмета исследования на основе осознания системности как существенного признака научного знания [6, 16].

В конце 1970-х годов проблема изучения музыкально-теоретических систем параллельно разрабатывалась Г. Вирановским. По мнению одесского музыковеда, внутренняя структура этого объекта изучения, направления и методы его анализа определяются такими аспектами исследования музыки, как: 1) совокупности звуковых форм; 2) художественной деятельности, особой формы общения; 3) совокупности ценностных, в частности эстетических, установок, которым в процессе художественной деятельности подчинено создание конкретных звуковых форм в рамках той или иной традиции $[1,9]$. В представленной концепции Г. Вирановского также чётко прослеживается тенденция к системности в изучении объекта исследования - музыкально-теоретической системы, что обусловлено, в первую очередь, иерархичной характеристикой его структуры и содержания.

По определению И. Котляревского, продолжившего развитие данного направления в музыкознании, «музыкально-теоретическая система есть продукт общественного сознания, являющийся целостной совокупностью представлений о сложившихся в музыкальной практике закономерностях отбора и организации звукового материала, а также факторах, обусловивщих эти закономерности» [3, 11]. В данном определении просматривается и иерархическая структура системы: уровень элементов, уровень связей, уровень целостности и методологическая направленность системы, «выражающаяся в синтезе музыкально-научного знания на базе единой для музыкально-художественного и теоретического мышления философской методологии» [3, 20].

Свою концепцию И. Котляревский обосновывает тем, что «системность научного знания есть отражение системности познаваемого объекта» $[3,17]$. При этом музыкально-теоретическая система, как объект познания, рассматривается на всех уровнях структуры в соответствии с диалектическими закономерностями взаимодействия теории и практики, последняя из которых является постоянно действующим фактором, от которого «зависят исторически конкретные формы решения центральной проблемы музыкально-теоретических систем» $[3,18]$. Показательно, что в данном контексте композиторская практика также структурируется в иерархическом порядке: уровень элементов, уровень связей и уровень целостности. Существенным представляется то, что эти три уровня являются не только 
действенными конструктивными моментами универсальной для теории и практики структуры, но и «определяют этапы анализа музыкально-теоретического знания» в его исторической эволюции [3, 21].

Идея системного подхода к изучению явлений музыкального искусства и культуры была признана в плане определённой перспективности и действенности её применения и получила продолжение своего развития в иной сфере, задекларировавшей себя как самостоятельное направление. Речь идёт об аналогичной (по отношению к музыкально-теоретическим системам) ситуации, которая сложилась в теории исполнительства, за которой на современном этапе закрепилась дефиниция «исполнительское музыкознание».

О. Лысенко обращает внимание на то, что если до сих пор объектом исследования были отдельные творческие персоналии, принципы отдельных исполнительских школ и направлений, то на современном этапе актуальной стала необходимость в изучении системных свойств музыкально-исполнительской культуры в целом. В связи с этим О. Лысенко предлагает такое определение: «Система музыкального профессионального исполнительства - исторически конкретное явление музыкальной практики, обусловленное общественным сознанием, которое является совокупностью представлений о закономерностях понимания организации звукового материала первичного творчества, которые сложились в музыкально-историческом процессе, и факторов, которые обуславливают эти закономерности» [4, 170]. Структура, в данном случае, в основных позициях аналогична структуре музыкально-теоретической системы с учётом корректив, обусловленных содержательно-смысловой спецификой исполнительского искусства как объекта исследования.

Системный подход к изучению профессионального музыкального исполнительства в концепции О. Лысенко проявляется в нескольких аспектах [4, 165-170], которые можно кратко изложить следующим образом:

1. Структура исполнительской деятельности: исполнитель текст - понимание - текстовоспроизведение.

2. Данная структура обуславливает, в свою очередь, функциональную систему «понимания музыкального текста», которая дифференцируется на подсистемные уровни: нотный текст - исполнительская рефлексия - звуковой текст.

3. Указанная функциональная система является одновременно частью структуры системы более высокого порядка: исполнительская 
практика - музыкально-теоретическая система - композиторское творчество.

4. Исполнительское искусство представляет собой своеобразную творческую форму познания музыкально-художественного явления, что органично включается в универсальную систему: познание - понимание - знание.

5. Исполнительская система в целом структурируется в соответствии с двумя основными подсистемами: исполнительской практикой и исполнительским знанием.

6. При изучении исполнительской практики особое значение имеет системная иерархия философского принципа классификации явлений: единичное - особенное - общее.

7. Иерархичность структуры исполнительской системы обусловливает её характеристику как подсистемы на более высоком уровне в зависимости от контекста исследования.

8. Особую организующую функцию при изучении данной проблемы выполняет системно-структурная модель исполнительского творчества как целостного объекта в 3-мерном описании: а) как функциональной части целого - музыкальной творческой практики; б) как целостного единства собственных специфически-исполнительских свойств и проявлений; в) как взаимосвязанной совокупности функционально и морфологично определённых подсистем в системе музыкального профессионального исполнительства.

К этому же направлению в исполнительском музыкознании относятся и научные разработки В. Сумароковой, подчёркивающей, что поскольку музыкальное исполнительство является целостным образованием творческой практики, то оно требует системного исследования [5, 180-181]. Главное отличие, в данном случае, заключается в самом объекте исследования: в центре внимания оказывается не исполнительское искусство как вид творческой деятельности, а собственно исполнительская школа как феномен музыкальной культуры. Структура системы при этом непосредственно связана с философско-методологической дифференциацией на частное (как авторское) - особое (как направление) - общее (как система алгоритмизации процесса обучения). Особое внимание В. Сумарокова обращает на то, что исполнительская школа «является элементом системы музыкального исполнительского искусства, исполнительской практики и, одновременно, представляет собой систему, обусловленную её функциональностью» $[5,186]$. Речь идёт о познавательной, коммуникативной и дидактической функци- 
ях, которые объективизируются в накоплении, систематизации, формализации определённого духовно-практического опыта, в создании правил и алгоритма разных видов творческой деятельности. Именно многофункциональность исполнительской школы как рода культурной традиции является основанием для применения системного подхода в изучении этого феномена музыкальной культуры.

После краткой характеристики наиболее ярких примеров применения системного подхода в исследовании явлений музыкального искусства логично обратиться к феномену композиторского творчества, т. е. непосредственно к системному пониманию музыкальной практики. Е. Котляревская предлагает следующее определение, дополняющее приведённые ранее согласно исторически и логически сложившейся триаде «композитор - исполнитель - исследователь»: «Музыкально-практическая система - исторически конкретный продукт общественного сознания, <...> который является совокупностью именно закономерностей отбора и организации звукового материала, а также факторов, которые обусловили эти закономерности» [2, 184]. Структура такой системы отличается от соответствующей структуры музыкально-теоретической системы так же, как фактический материал отличается от его интерпретации.

Все приведённые определения находятся в соответствии с лаконичной и одновременно достаточно ёмкой философско-обобщающей дефиницией понятия «система» - это совокунность элементов в их взаимодействии и композиции. При этом особое значение имеет принцип так называемого относительно-дополнительного «видения» музыкального явления. Иными словами, каждое такое явление рассматривается и как самостоятельная система, и как элемент (т. е. «подсистема») более высокой по уровню организации метасистемы.

Выводы. В связи с вышесказанным предлагается вариант методической организации анализа музыкального произведения, поэтапную основу которого составляют логические принципы многоуровневого иерархического структурирования объекта исследования, т. е. произведения, как системы:

- уровень элементов, т. е. специфика средств музыкальной выразительности, отбор которых обусловлен характером и формой музицирования;

- уровень связей, характеризующий различные формы организации элементов музыкального языка и средств музыкальной выразительности; 
- уровень целостности, представляющий композицию и драматургию музыкального произведения во всей множественности связей и свойств элементов;

- уровень смыслополагания как высшая форма «познания-понимания» музыкального произведения с точки зрения своеобразной «расшифровки» культурно-исторической, философско-эстетической и эмоционально-психологической информации, определяющей духовную ценностность объекта исследования.

Обратим внимание, что первые три уровня совпадают с соответствующими уровнями в приведённых выше структурах музыкально-теоретической и музыкально-практической систем. Четвёртый уровень, в данном случае, представляет собой не своеобразный конструктивно-концепционный (т. е. методологический) стержень исследования, как в концепции И. Котляревского. В контексте представленной методики речь идёт о смыслополагании как гипотетическом представлении о композиторской интерпретации индивидуального мировоззрения, обусловленного субъективным осознанием системы мироотношений, которая объективируется в музыкальной картине мира.

Безусловно, что такой методический подход связан, в первую очередь, с понятием «стиль», как системы устойчивых признаков какого-либо явления. На протяжении развития музыкального искусства и теоретической мысли наблюдается закономерный процесс своеобразного «сжатия», как бы «концентрации» представлений об определённых персоналиях, исторических периодах и даже целых эпохах. Такое обобщение знания - от характеристики творчества отдельных композиторов до осознания более масштабных целостностей - позволяет говорить о стиле эпохи, стиле направления, течения, школы и, наконец, об индивидуальном стиле композитора. Очевидно, что речь идёт о формировании представления об определённых музыкально-практических системах. При этом остаётся фактом, что практически каждое музыкальное произведение является, в определённой мере, уникальным, т. е. единичным решением конкретной творческой сверхзадачи. Именно эта позиция предполагает введение такого понятия, как «музыкально-практическая концепция», представляющая собой частное проявление общих закономерностей, подчёркивающее индивидуальность и неповторимость каждого произведения и, естественно, каждой творческой личности. При этом нельзя не отметить, что любая личность существует не изолировано, а 
живёт и творит в конкретном культурно-историческом и социальнообщественном контексте, который так или иначе оказывает на неё определённое влияние именно в мировоззренческом плане. Поэтому, несмотря на неизбежность персонификации и индивидуализации, в творчестве даже самых разных композиторов можно выявить общие черты, на основе чего делаются выводы о существовании определённых художественно-эстетических тенденций, течений, направлений, периодов, эпох, т. е. стилевых систем.

Такой закономерно-логический переход от единичного к общему, что является основным ориентиром в предложенном выше методическом подходе, позволяет систематизировать изучение тотального разнообразия на всех уровнях музыкально-эстетической целостности от «микроэлементов» до формирования художественной картины мира.

\section{СПИСОК ЛИТЕРАТУРЫ}

1. Вірановський Г. Музично-теоретичні системи (предмет і принципи побудови. К.: Музична Україна, 1978. 87 с.

2. Котляревська О. Теоретичні та практичні музичні системи вїх історичній взаємодії // Актуальні проблеми мистецької практики і мистецтвознавчої науки. Мистецькі обрії'2009. 2009. Вип. 2 (11). С. 183-185.

3. Котляревский И. Музыкально-теоретические системы европейского искусствознания. Методы изучения и классификации. К.: Музична Україна, 1983. $158 \mathrm{c}$.

4. Лисенко О. Музичне виконавство та проблема його системного вивчення // Науковий вісник. Музикознавство: з XX у XXI століття. 2000. Вип. 7. C. $162-171$.

5. Сумарокова В. Виконавська школа як об'єкт дослідження: до визначення поняття Сумарокова // Науковий вісник НМАУ ім. П. І. Чайковського: Музичне виконавство. 2004. Вип. 40. Книга десята. С. 180-190.

6. Холопов Ю. Музыкально-теоретические системы: Программа для музыкальных вузов по специальности № № 2207, 2208 «Композиция», «Музыковедение» / сост. д-р искусствоведения, и.о. профессора Холопов Ю. Н. М., 1982. 61 с.

\section{REFERENCES}

1. Viranovsky, G. (1978). Musical-theoretical systems (subject and principles of construction). K.: Musichna Ukraina [in Ukrainian].

2. Kotlyarevskaya, O. (2009). Theoretical and practical musical systems in their historical interaction. Actual problems of artistic practice and art critic science. Artistic horizons'. (Issue 2 (11)), (pp. 183-185) [in Ukrainian].

3. Kotlyarevsky, I. (1983). Musical and theoretical systems of the European Art Studies. Methods of studying and classification. K.: Musichna Ukraina [in Russian]. 
4. Lysenko, O. (2000). Musical performance and the problem of his systematic study. Scientific Herald. Musicology: from the XX century to the XXI century (Issue 7), (pp. 162-171) [in Ukrainian].

5. Sumarokova, V. (2004). Performing school as an object of research: to define the concept. Scientific herald of National P. I. Tchaikovsky Academy of Music. (Issue. 40/10), (pp. 180-190) [in Ukrainian].

6. Kholopov, Yu. (1982). Musical and theoretical systems: The program for musical higher education institutions. in No. No. 2207, 2208 «Composition», «Musicology» [in Russian].

Стаття надійциа до редакції 08.06.2016

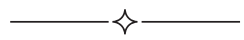

УДК 78.01/.071.2/.072.2+782.1

УХуйминь, соискатель кафедры теории музыки и композиции

ОНМА им. А. В. Неждановой

odma_n@ukr.net

\title{
ПСИХОЛОГИЧЕСКИЕ ПРЕДПОСЫЛКИ И УСЛОВИЯ ОПЕРНОЙ ВОКАЛЬНО-ИНТОНАЦИОННОЙ ИНТЕРПРЕТАЦИИ
}

\begin{abstract}
Цель работы - обосновать необходимость привлечения теории и методических принципов психологического театра в опероведение, раскрыть предпосылки и пути использования системы К. Станиславского в оперном творчестве, в совершенствовании оперной драматургии. Методология исследования предполагает синтез театроведческого $и$ музыковедческого подхода, дискурс-анализа применительно к учению К. Станиславского и В. Немировича-Данченко и психологии искусства. Научная новизна статьи состоит в развитии и расширении психологического подхода к оперной вокально-интонационной интерпретации как $\kappa$ артистической музыкально-театральной деятельности, в углублении со стороны опероведения представления о психологическом театре как особом художественно-творческом феномене. Выводы работы позволяют определять основные интерпретативные задачи режиссера, дирижера и певца-артиста, организующих оперную постановку, обнаруживать их специфику и художественно-смысловое единство.
\end{abstract}

Ключевые слова: психологический театр, система К. Станиславского, певец-артист, интерпретация, опероведение, оперное смыслообразование, оперное образно-сиеническое выражение. 